\title{
INTRODUCTION
}

\section{Sustainable management of populations impacted by harvesting and climate change}

\author{
Nils Chr. Stenseth ${ }^{1, *}$, Rolf A. Ims ${ }^{2}$, Bernt-Erik Sæther ${ }^{3}$, Luis Cadahía ${ }^{1, \#,}$ \\ Ivar Herfindal ${ }^{3, \#}$, Aline Magdalena Lee ${ }^{3, \#}$, Jason D. Whittington ${ }^{1, \#}$, Nigel G. Yoccoz ${ }^{2, \#}$ \\ ${ }^{1}$ Centre for Ecological and Evolutionary Synthesis, Department of Biosciences, University of Oslo, 0316 Oslo, Norway \\ ${ }^{2}$ Department of Arctic and Marine Biology, UiT the Arctic University of Norway, 9037 Tromsø, Norway \\ ${ }^{3}$ Centre for Biodiversity Dynamics, Department of Biology, Norwegian University of Science and Technology, \\ 7491 Trondheim, Norway
}

\begin{abstract}
The sustainable use of natural resources is critical for addressing the global challenges of today. Strategies for sustainable harvesting need to consider not only harvested species, but also other non-harvested species interacting with them in the same ecosystem. In addition, environmental variation needs to be considered, with climate change currently being one of the main sources of this variation. Understanding the consequences of complex interactions between different drivers and processes affecting dynamics of species and ecosystems across spatial scales requires large-scale integrative research projects. The Norwegian research initiative "Sustainable management of renewable resources in a changing environment: an integrated approach across ecosystems" (SUSTAIN) was launched to fill knowledge gaps related to the sustainable management of populations and ecosystems experiencing climate change. SUSTAIN investigated terrestrial, marine and freshwater ecosystems in boreal and Arctic regions, using both theoretical developments and empirical analyses of long-term data. This Climate Research Special contains both synthesis articles and original research exemplifying some of the approaches used in SUSTAIN. In this introduction we highlight 4 key topics addressed by SUSTAIN: (i) population structure, (ii) interactions between species, (iii) spatial processes, and (iv) adaptive management. These topics are fundamental to the understanding of harvested species from an ecosystem perspective, and to ecosystem-based management approaches, which we are striving to work towards.
\end{abstract}

KEY WORDS: Sustainable harvesting $\cdot$ Yield $\cdot$ Population synchrony $\cdot$ Strategic foresight protocol

\section{CHALLENGES}

Sustainable use of natural resources is critical for addressing the global challenges of today, not least because exploitation of nature has put humanity in a critical situation due to severe degradation of ecosystems (IPBES 2019). Several of the UN Sustainable Development Goals (SDG), such as SDG2 (zero hunger) or SDG6 (clean water and sanitation), directly

\footnotetext{
*Corresponding author: n.c.stenseth@mn.uio.no
}

\# These authors contributed equally depend on well-functioning ecosystems (SDG14: life below water; SDG15: life on land) and their services (Blicharska et al. 2019). Harvesting of natural resources in ways that are sustainable both for the affected species and their ecosystems is therefore a win-win goal for both nature and humans. However, harvesting of species fluctuating in environments that are also systematically changing at unprecedented rates, presents particular challenges for sus-

() The authors 2022. Open Access under Creative Commons by Attribution Licence. Use, distribution and reproduction are unrestricted. Authors and original publication must be credited. 
tainable management and for maintaining ecosystem functions.

In stable environments, maintaining sustainable harvesting of individual species requires different strategies than those maximizing the yield (Beddington \& May 1977, May et al. 1978, Lande et al. 1995, 1997). Ecosystem-based management has been promoted as the most relevant framework to account for interactions among species and the harvesting of multiple species (Levin et al. 2009, Katsanevakis et al. 2011, Lee et al. 2022 in this Special). Climate change has become a main source of environmental variability, and this poses challenges, as it shifts species and ecosystems beyond known regimes of stochastic fluctuations in the environment (novel climate) and species-interactions (novel ecosystems). Although these topics have received considerable attention in the literature, there are few integrative studies and large knowledge gaps remain. Understanding the consequences of complex interactions between different drivers and processes affecting dynamics of species and ecosystems across spatial scales requires large-scale integrative research projects.

The Norwegian research initiative "Sustainable management of renewable resources in a changing environment: an integrated approach across ecosystems" (SUSTAIN) was launched to fill knowledge gaps related to the sustainable management of populations and ecosystems that experience climate change - with a particular emphasis on interacting factors such as population structure and species interactions. SUSTAIN investigated terrestrial, marine and freshwater ecosystems in boreal and Arctic regions (Fig. 1), and was organized around seven case studies within these 3 main ecosystems, including: (1) semi-domestic reindeer in alpine and sub-arctic ecosystems, (2) reindeer, rock ptarmigan and arctic fox in high-arctic tundra, (3) willow ptarmigan in sub-arctic and low-arctic tundra, (4) increasing red fox populations in a tundra ecosystem, (5) moose and small game in boreal forests, (6) fish stocks in the Mjøsa lake, and (7) fish stocks in the Barents Sea. The work included both theoretical developments and empirical analyses of long-term data. This Climate Research Special contains both synthesis articles of the overall work done within SUSTAIN and original research articles that exemplify some of the approaches that were employed.

In this introduction we highlight 4 key topics addressed by SUSTAIN, and also emphasized in the articles included in this Climate Research Special: (i) population structure, (ii) interactions between species, (iii) spatial processes, and (iv) adaptive management. These topics are fundamental to the understanding of harvested species from an ecosystem perspective, and to developing ecosystem-based management approaches.

\section{POPULATION STRUCTURE}

Population structure, such as age, size and sex structure, plays an important role in determining how harvesting influences population dynamics (Sæther et al. 2001). Different segments of a population (e.g. different gender, age classes) often experience different risks of being harvested (Markussen et al. 2018, 2019, Stubberud et al. 2019). Such biased or selective harvesting is often intentional (e.g. harvest of individuals of specific age or size; Kuparinen \& Festa-Bianchet 2017, Nater et al. 2020, Peeters et al. 2022 in this Special), but can also be an unintentional consequence of the way harvesting is carried out (e.g. when harvest is concentrated in areas used by certain types of individuals; Ofstad et al. 2020). Herfindal et al. (2022a in this Special) illustrate how biased harvesting causes fluctuations in the population structure from an individual-based long-term study of an island moose population.

Effects of environmental variation and change on individuals within the population are also known to differ among groups of individuals (Coulson 2001, Sæther et al. 2013, Bleu et al. 2015). Such environmental effects on population dynamics may be delayed when important mediators such as body condition link to weather in one season/year and to e.g. reproduction the next season/year (Herfindal et al. 2015, Henden et al. 2022 in this Special, Nater et al. 2022 in this Special). Thus, the overall impact of environmental variation on population dynamics depends on how sensitive different classes of individuals are to impacts of both harvesting and environmental changes. In some cases, harvesting targets those individuals that are also being most impacted by climate change; in other cases, selective harvesting biases population structure towards individuals that are more sensitive to environmental variation (Berkeley et al. 2004, Rouyer et al. 2011). Explicit consideration of such effects is crucial to avoid unwanted population responses due to harvesting (Gamelon et al. 2019, Lee et al. 2022). In this context, the application of state-of-the art analytical techniques is essential for studies that consider how population structure and life history adaptations affect the resilience of species both to harvesting and to environmental change (e.g. Stubberud et al. 2022 in this Special). 


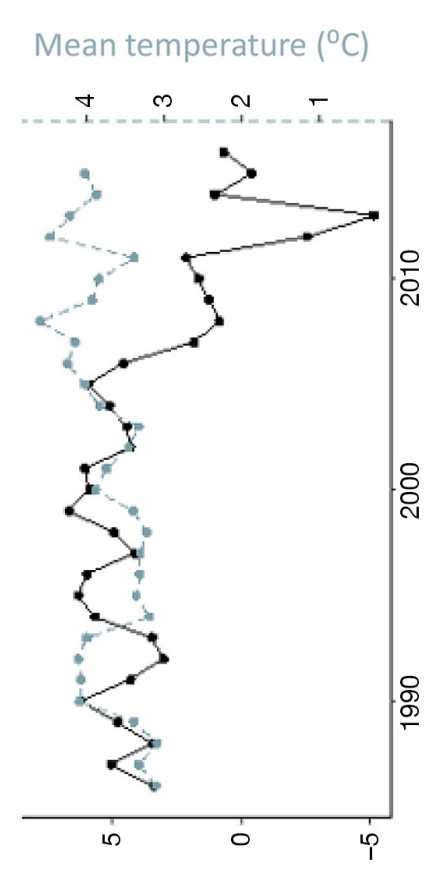

Polar cod log density (catch numbers)
Lake temperature $\left({ }^{\circ} \mathrm{C}\right)$

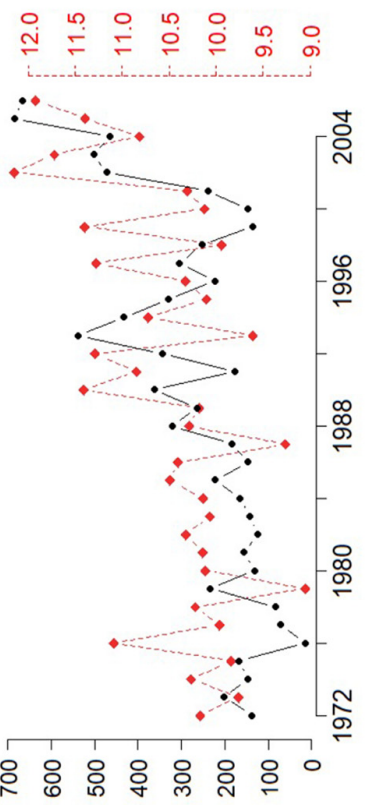

Trout captures

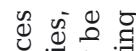

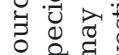

D. 0 .

Winter temperature $\left({ }^{\circ} \mathrm{C}\right)$

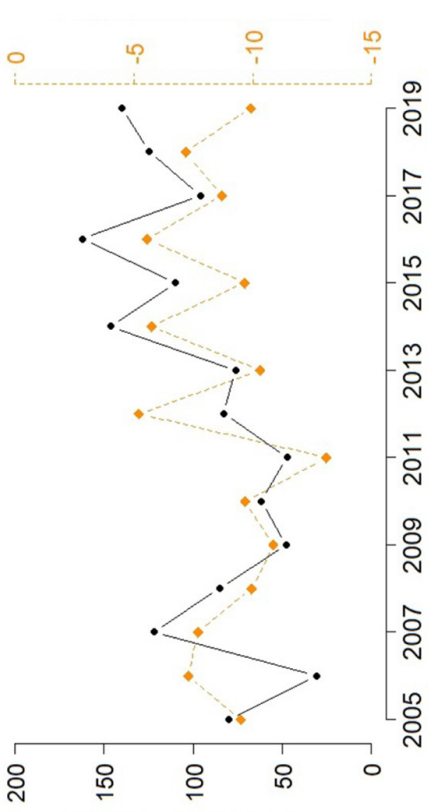

Ptarmigan counts

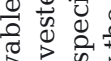

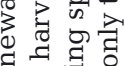

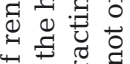

금 륭. 형

过 명

号苛

T.

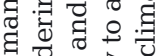

Q

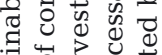

वै

जी

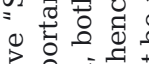

过

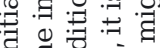

a

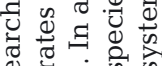

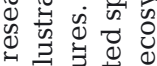

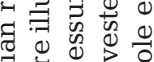

㐘范范

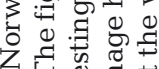

它它范

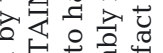

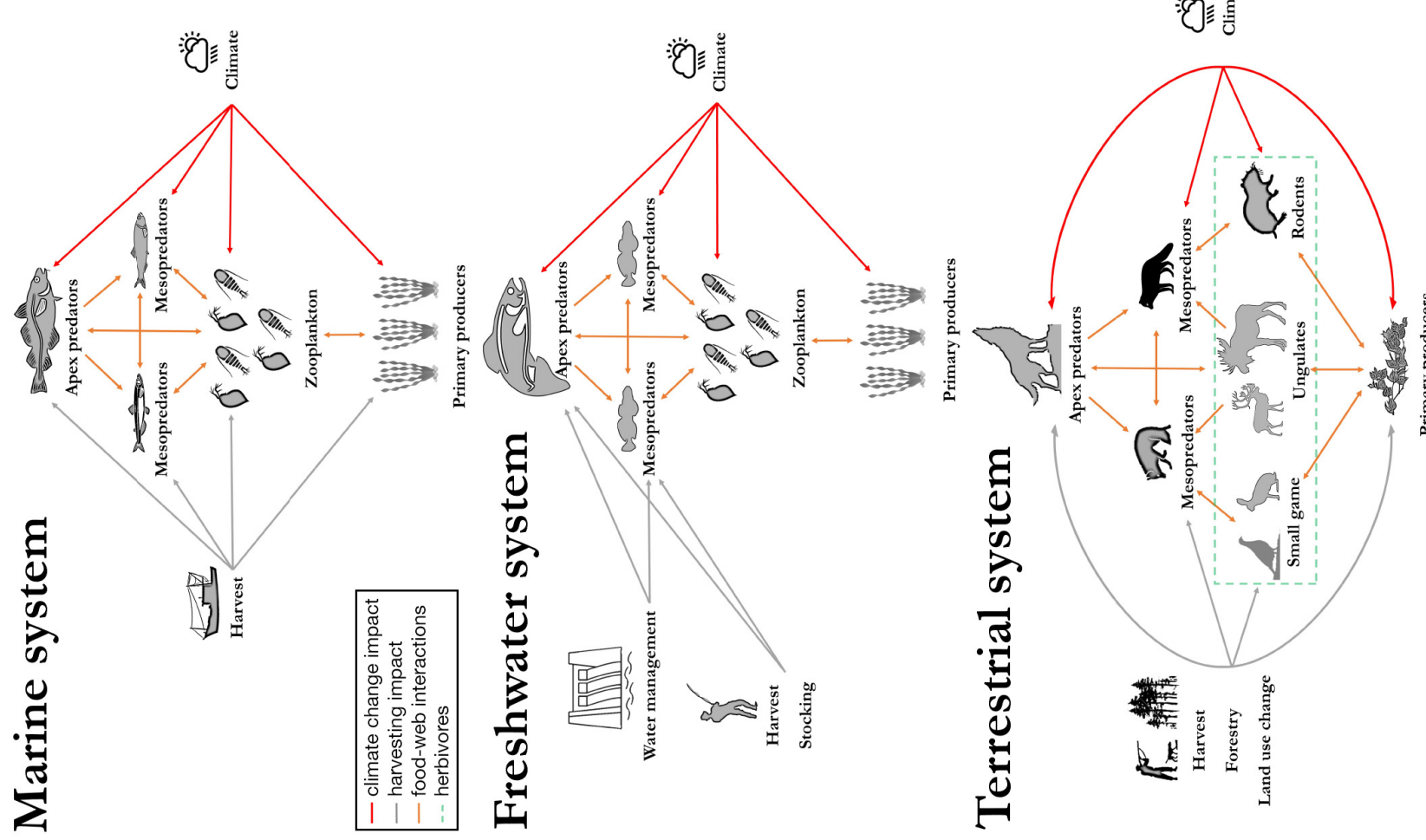

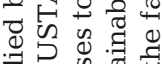

品

ज力 is on है

दै है वृ

w w

गु

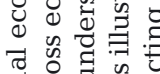

蛋

ब。

造

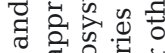

- 0 讨

to

敋

$0 . \bar{g}=0$

० 주웡

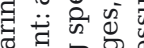

वृ वै

켱 ఫ्चु

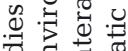

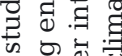

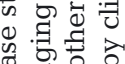

U 중

- $\rightarrow$ है तै है है

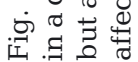




\section{INTERACTIONS BETWEEN SPECIES}

Natural systems consist of many species that interact with each other in complex ways. Thus, the population dynamics and responses to harvesting and environmental change of one species depend on the dynamics and responses of other species within the ecosystem (Anderwald et al. 2015, Gamelon et al. 2020). This interdependence calls for a multi-species or ecosystem approach to manage harvesting (Levin et al. 2009). Single species harvesting quotas can have serious and detrimental consequences in systems of interacting species, in particular when more than one species is harvested simultaneously (Legović et al. 2010). In fact, in some cases annual yields can be optimized when different types of harvesting strategies are used on different species. Bellier et al. (2021) found that applying proportional harvesting to a prey species and proportional threshold harvesting to its predator gave optimal results when species-specific responses to the environment were accounted for. We know that climate warming can change species interactions and restructure food webs (Bartley et al. 2019, Pecuchet et al. 2020, Tanentzap et al. 2020), making these effects even more complex. Mellard et al. (2022 in this Special), who provide a synthesis of SUSTAIN studies on Arctic harvested species, conclude that adding the food web dimension to predicting changes in harvested population sizes may or may not improve near-term predictions (see also Henden et al. 2020, Marolla et al. 2021). This may be due to data limitation, for instance, leading to inadequate approximations of species interaction in the prediction models. Moreover, multi-driver impacts on complex communities - composed of many interacting species with divergent phenologies - represent a challenge for both establishing causality and making predictions (Moe et al. 2022 in this Special).

\section{SPATIAL PROCESSES}

Spatial processes involving movement of individuals among localities (e.g. migration and dispersal), along with geographical covariation in the environment, are important for both population dynamics and harvesting yield. Thus, these have been key topics addressed in the SUSTAIN project (Herfindal et al. 2022b in this Special, Melsom et al. 2022 in this Special). The influence of harvesting on population synchrony (see Herfindal et al. 2022c in this Special, Lee et al. 2022) is one spatial process which has only recently received more attention. Shared environ- mental fluctuations, for instance in weather, are known to cause synchronized population dynamics, sometimes over large areas (Moran 1953, Koenig 2002, Walter et al. 2017). Such patterns of spatial synchrony are expected to change as the climate warms (Hansen et al. 2019). Since the spatial scaling of environmental variation is different in marine, limnic and terrestrial systems (Herfindal et al. 2022b,c), climate change-induced changes in population synchrony may also differ among these environments.

Increased population synchrony enhances the global extinction risk (Heino et al. 1997, Earn et al. 2000). However, even if species within a given area and system are experiencing the same environmental conditions, they do not necessarily show the same degree of population synchrony. Differences in the degree of spatial synchrony in population fluctuations are related to dispersal (Lande et al. 1999), life history strategy (Marquez et al. 2019), interspecific interactions (Lee et al. 2020), age structure (Marquez et al. 2021) and sensitivity to environmental variables (Hansen et al. 2019, Herfindal et al. 2020). In addition, the choice of harvesting strategy can strongly influence the patterns of synchronized fluctuations in the size of populations separated in space, sometimes increasing (Engen et al. 2018a,b, Jarillo et al. 2018) and sometimes reducing it (Engen et al. 2018a). Furthermore, population synchrony is influenced by species interactions, and harvest effects on one species can influence the population synchrony of interacting species (Jarillo et al. 2018, 2020), even if they are not harvested (Jarillo et al. 2018). Reviewing different harvest strategies, Lee \& Sæther (2022 in this Special) suggest that proportional threshold harvesting may be a good starting point for adapting harvesting strategies in the context of populations and ecosystems subjected to climate change.

\section{ADAPTIVE MANAGEMENT}

Adaptive management will become increasingly important as climate change causes regime shifts in many ecosystems (Walters 2007). SUSTAIN case studies have dealt with several essential elements of adaptive management, such as strategies for implementing and estimating the effects of management interventions (Marolla et al. 2021, Henden et al. 2022, Nater et al. 2022, Peeters et al. 2022), adapting harvesting strategies to a changing climate (Gamelon et al. 2019, Lee \& Sæther 2022, Lee et al. 2022) and the important dialogue between researchers, managers and other stakeholders (Henden et al. 2020, 
Mellard et al. 2022). With respect to the latter point, SUSTAIN implemented a Strategic Foresight Protocol (Cook et al. 2014) in its case studies and Hamel et al. (2022 in this Special) summarize the experiences with this protocol. Experience with the Strategic Foresight Protocol demonstrates that the success of such an endeavor depends on the willingness of the people involved, which in turn depends on their availability and opportunities to meet on common ground (both geographically and otherwise). In addition, building social capital among all directly involved participants from the beginning of the process is essential for building the trust needed to ensure an effective functioning among social groups with different interests and values, as has been the case with SUSTAIN. In the most successful cases (e.g. Henden et al. 2020), such a structured way of interacting with stakeholders has had significant influences on the research, and increased the likelihood that SUSTAIN's science will be helpful to the management of species and ecosystems subjected to climate change.

\section{THE BROADER CONTRIBUTION OF SUSTAIN}

The integrated approach of SUSTAIN clearly shows that management strategies for exploited species must take the expected climatic changes into account. SUSTAIN has, through its comparisons across ecosystems, identified some general points that should be included in developing such sustainable management principles. First, it is necessary to disentangle the effects of harvest from the effects of variation in environmental conditions on population dynamics. Climate change complicates this, requiring more detailed analyses and even better data than previously collected to reduce unintended negative consequences of harvesting, such as population collapse or increased variability in annual yields. Second, alterations of the geographical distribution of exploited species, e.g. caused by changes in climate, can influence species interactions and population fluctuations over large areas. The results from SUSTAIN clearly indicate that an ecosystem-based management strategy must include a spatial perspective that also incorporates non-harvested species. Finally, because future management plans for exploited species must respond to potential environmental changes, adaptive management is key. This approach requires stronger interactions between managers, end-users, and researchers. The Strategic Foresight Protocol used in SUSTAIN illustrates one way to formalize such interactions.
Acknowledgements. We thank the entire SUSTAIN team for their great contribution to the SUSTAIN project. We also thank Filippo Marolla for creating Fig. 1 in this introduction. We are grateful to the Research Council of Norway (RCN) for generous support to the SUSTAIN project. We also thank the Centre for Ecological and Evolutionary Synthesis in the Department of Biosciences at the University of Oslo, the Department of Arctic and Marine Biology at the UiT the Arctic University of Norway and the Centre for Biodiversity Dynamics in the Department of Biology at the Norwegian University of Science and Technology for various support. Finally we thank the Editor-in-Chief, Mikhail Semenov, and the 4 (Guest) Editors of this Special, Nils Bunnefeld, Tim Coulson, Christian Damgaard and Tim Sparks for their excellent editorial work.

\section{LITERATURE CITED}

Anderwald P, Herfindal I, Haller RM, Risch AC, Schütz M, Schweiger AK, Filli F (2015) Influence of migratory ungulate management on competitive interactions with resident species in a protected area. Ecosphere 6:art228

Bartley TJ, McCann KS, Bieg C, Cazelles K and others (2019) Food web rewiring in a changing world. Nat Ecol Evol 3:345-354

*Beddington JR, May RM (1977) Harvesting natural populations in a randomly fluctuating environment. Science 197:463-465

Bellier E, Sæther BE, Engen S (2021) Sustainable strategies for harvesting predators and prey in a fluctuating environment. Ecol Modell 440:109350

Berkeley SA, Hixon MA, Larson RJ, Love MS (2004) Fisheries sustainability via protection of age structure and spatial distribution of fish populations. Fisheries (Bethesda, Md) 29:23-32

Bleu J, Herfindal I, Loison A, Kwak AMG and others (2015) Age-specific survival and annual variation in survival of female chamois differ between populations. Oecologia 179:1091-1098

* Blicharska M, Smithers RJ, Mikusiński G, Rönnbäck P, Harrison PA, Nilsson M, Sutherland WJ (2019) Biodiversity's contributions to sustainable development. Nat Sustain 2: 1083-1093

* Cook CN, Inayatullah S, Burgman MA, Sutherland WJ, Wintle BA (2014) Strategic foresight: how planning for the unpredictable can improve environmental decisionmaking. Trends Ecol Evol 29:531-541

Coulson T, Catchpole EA, Albon SD, Morgan BJT and others (2001) Age, sex, density, winter weather, and population crashes in Soay sheep. Science 292:1528-1531

Earn DJ, Levin SA, Rohani P (2000) Coherence and conservation. Science 290:1360-1364

* Engen S, Cao FJ, Sæther BE (2018a) The effect of harvesting on the spatial synchrony of population fluctuations. Theor Popul Biol 123:28-34

Engen S, Lee AM, Sæther BE (2018b) Spatial distribution and optimal harvesting of an age-structured population in a fluctuating environment. Math Biosci 296:36-44

* Gamelon M, Sandercock BK, Sæther BE (2019) Does harvesting amplify environmentally induced population fluctuations over time in marine and terrestrial species? J App Ecol 56:2186-2194

Gamelon M, Filli F, Sæther BE, Herfindal I (2020) Multievent capture-recapture analysis in Alpine chamois 
reveals contrasting responses to interspecific competition, within and between populations. J Anim Ecol 89: 2279-2289

Hamel S, Ims RA, Yoccoz NG (2022) Challenges and opportunities when implementing strategic foresight: lessons learned when engaging stakeholders in climate-ecological research. Clim Res 86:29-35

Hansen BB, Pedersen Å , Peeters B, Le Moullec M and others (2019) Spatial heterogeneity in climate change effects decouples the long-term dynamics of wild reindeer populations in the high Arctic. Glob Change Biol 25:3656-3668

Heino M, Kaitala V, Ranta E, Lindström J (1997) Synchronous dynamics and rates of extinction in spatially structured populations. Proc R Soc B 264:481-486

Henden JA, Ims RA, Yoccoz N, Asbjørnsen EJ and others (2020) End-user involvement to improve predictions and management of populations with complex dynamics and multiple drivers. Ecol Appl 30:e02120

Henden JA, Tveraa T, Stien A, Mellard JP, Marolla F, Ims RA, Yoccoz NG (2022) Direct and indirect effects of environmental drivers on reindeer reproduction. Clim Res 86: 179-190

KHerfindal I, van de Pol M, Nielsen JT, Sæther BE, Møller AP (2015) Climatic conditions cause complex patterns of covariation between demographic traits in a long-lived raptor. J Anim Ecol 84:702-711

Herfindal I, Tveraa T, Stien A, Solberg EJ, Grøtan V (2020) When does weather synchronize life-history traits? Spatiotemporal patterns in juvenile body mass of two ungulates. J Anim Ecol 89:1419-1432

Herfindal I, Lee AM, Hamel S, Solberg EJ, Sæther BE (2022a) Demographic consequences of harvesting: a case study from a small and isolated moose population. Clim Res 86:53-64

Herfindal I, Aanes S, Benestad R, Finstad AG, Salthaug A, Stenseth NC, Sæther BE (2022b) Spatiotemporal variation in climatic conditions across ecosystems. Clim Res 86:9-19

Herfindal I, Lee AM, Marquez JF, Le Moullec M and others (2022c) Environmental effects on spatial population dynamics and synchrony: lessons from northern ecosystems. Clim Res 86:113-123

Intergovernmental Science-Policy Platform on Biodiversity and Ecosystem Services (IPBES) (2019) Global assessment report on biodiversity and ecosystem services of the Intergovernmental Science-Policy Platform on Biodiversity and Ecosystem Services. Brondízío ES, Settele J, Díaz S, Ngo HT (eds), IPBES secretariat, Bonn

Jarillo J, Sæther BE, Engen S, Cao FJ (2018) Spatial scales of population synchrony of two competing species: effects of harvesting and strength of competition. Oikos 127: 1459-1470

Jarillo J, Sæther BE, Engen S, Cao-García FJ (2020) Spatial scales of population synchrony in predator-prey systems. Am Nat 195:216-230

Katsanevakis S, Stelzenmüller V, South A, Sørensen TK and others (2011) Ecosystem-based marine spatial management: review of concepts, policies, tools, and critical issues. Ocean Coast Manage 54:807-820

Koenig WD (2002) Global patterns of environmental synchrony and the Moran effect. Ecography 25:283-288

Kuparinen A, Festa-Bianchet M (2017) Harvest-induced evolution: insights from aquatic and terrestrial systems. Philos Trans R Soc Lond B Biol Sci 372:20160036
Lande R, Engen S, Sæther BE (1995) Optimal harvesting of fluctuating populations with a risk of extinction. Am Nat 145:728-745

Lande R, Sæether BE, Engen S (1997) Threshold harvesting for sustainability of fluctuating resources. Ecology 78 : 1341-1350

* Lande R, Engen S, Sæther BE (1999) Spatial scale of population synchrony: environmental correlation versus dispersal and density regulation. Am Nat 154:271-281

Lee AM, Sæther BE (2022) Optimal harvesting in a changing climate. Clim Res 86:21-27

* Lee AM, Sæther BE, Engen S (2020) Spatial covariation of competing species in a fluctuating environment. Ecology 101:e02901 doi:10.1002/ecy.2901

Lee AM, Jarillo J, Peeters B, Hansen BB, Cao-Garcìa FJ, Sæther BE, Engen S (2022) Population responses to harvesting in fluctuating environments. Clim Res 86: $79-91$

KLegović T, Klanjšček J, Geček S (2010) Maximum sustainable yield and species extinction in ecosystems. Ecol Modell 221:1569-1574

* Levin PS, Fogarty MJ, Murawski SA, Fluharty D (2009) Integrated ecosystem assessments: developing the scientific basis for ecosystem-based management of the ocean. PLoS Biol 7:e1000014

Markussen SS, Loison A, Herfindal I, Solberg EJ and others (2018) Fitness correlates of age at primiparity in a hunted moose population. Oecologia 186:447-458

Markussen SS, Herfindal I, Loison A, Solberg EJ and others (2019) Determinants of age at first reproduction and lifetime breeding success revealed by full paternity assignment in a male ungulate. Oikos 128:328-337

* Marolla F, Henden JA, Fuglei E, Pedersen ÅØ, Itkin M, Ims RA (2021) Iterative model predictions for wildlife populations impacted by rapid climate change. Glob Change Biol 27:1547-1559

Marquez JF, Lee AM, Aanes S, Engen S, Herfindal I, Salthaug A, Sæther BE (2019) Spatial scaling of population synchrony in marine fish depends on their life history. Ecol Lett 22:1787-1796

* Marquez JF, Sæther BE, Aanes S, Engen S, Salthaug A, Lee AM (2021) Age-dependent patterns of spatial autocorrelation in fish populations. Ecology e03523

May RM, Beddington JR, Horwood JW, Shepherd JG (1978) Exploiting natural populations in an uncertain world. Math Biosci 42:219-252

Mellard JP, Henden JA, Pedersen Å, Marolla F, Hamel S, Yoccoz NG, Ims RA (20221) Food web approach for managing Arctic wildlife populations in an era of rapid environmental change. Clim Res 86:163-178

Melsom A, Kvile KØ, Dagestad KF, Broström G, Langangen $\varnothing$ (2022) Exploring drift simulations from ocean circulation experiments: application to cod eggs and larval drift. Clim Res 86:145-162

Moe SJ, Hobæk A, Persson J, Skjelbred B, Løvik JE (2022) Shifted dynamics of plankton communities in a restored lake: exploring the effects of climate change on phenology through four decades. Clim Res 86:125-143

Moran PAP (1953) The statistical analysis of the Canadian lynx cycle. Aust J Zool 1:291-298

*Nater CR, Vindenes Y, Aass P, Cole D and others (2020) Size- and stage-dependence in cause-specific mortality of migratory brown trout. J Anim Ecol 89:2122-2133

Nater CR, Stubberud MW, Langangen $\varnothing$, Rustadbakken A and others (2022) Towards a future without stocking: har- 
vest and river regulation determine long-term population viability of migratory salmonids. Clim Res 86:37-52

Ofstad EG, Markussen SS, Sæther BE, Solberg EJ and others (2020) Opposing fitness consequences of habitat use in a harvested moose population. J Anim Ecol 89:1701-1710

Pecuchet L, Blanchet MA, Frainer A, Husson B, Jørgensen LL, Kortsch S, Primicerio R (2020) Novel feeding interactions amplify the impact of species redistribution on an Arctic food web. Glob Change Biol 26:4894-4906

Peeters B, Ønvik Pedersen A, Veiberg V, Bremset Hansen B (2022) Hunting quotas, selectivity and stochastic population dynamics challenge the management of wild reindeer. Clim Res 86:93-111

Rouyer T, Ottersen G, Durant JM, Hidalgo M and others (2011) Shifting dynamic forces in fish stock fluctuations triggered by age truncation? Glob Change Biol 17: 3046-3057

Sæther BE, Engen S, Solberg EJ (2001) Optimal harvest of age-structured populations of moose Alces alces in a fluctuating environment. Wildl Biol 7:171-179
Sæther BE, Coulson T, Grøtan V, Engen S and others (2013) How life history influences population dynamics in fluctuating environments. Am Nat 182:743-759

Stubberud MW, Vindenes Y, Vøllestad LA, Winfield IJ, Stenseth NC, Langangen $\varnothing$ (2019) Effects of size- and sex-selective harvesting: an integral projection model approach. Ecol Evol 9:12556-12570

Stubberud MW, Nater CR, Vindenes Y, Vøllestad LA, Langangen $\varnothing$ (2022) Low impact of first-time spawners on population growth in a brown trout population. Clim Res 86:65-78

* Tanentzap AJ, Morabito G, Volta P, Rogora M, Yan ND, Manca M (2020) Climate warming restructures an aquatic food web over 28 years. Glob Change Biol 26: 6852-6866

* Walter JA, Sheppard LW, Anderson TL, Kastens JH, Bjørnstad ON, Liebhold AM, Reuman DC (2017) The geography of spatial synchrony. Ecol Lett 20:801-814

Walters CJ (2007) Is adaptive management helping to solve fisheries problems? Ambio 36:304-307 